\title{
Role of Information and Communication Technology in Green Supply Chain Implementation and Companies' Performance
}

\author{
José Roberto Mendoza-Fong ${ }^{1, *(\mathbb{D})}$, Jorge Luis García-Alcaraz ${ }^{2}$ (D), Emilio Jiménez Macías ${ }^{3}$ (D), \\ Nancy Liliana Ibarra Hernández ${ }^{2}$, José Roberto Díaz-Reza ${ }^{1}$ (D) and Julio Blanco Fernández ${ }^{4}$ (i) \\ 1 Department of Electrical Engineering and Computing, Autonomous University of Ciudad Juarez, \\ Juarez 32310, Mexico; al164440@alumnos.uacj.mx \\ 2 Department Industrial Engineering and Manufacturing, Autonomous University of Ciudad Juarez, \\ Juarez 32310, Mexico; jorge.garcia@uacj.mx (J.L.G.-A.); al160629@alumnos.uacj.mx (N.L.I.H.) \\ 3 Department Electrical Engineering, University of La Rioja, 26004 Logroño, Spain; emilio.jimenez@unirioja.es \\ 4 Department Mechanical Engineering, University of La Rioja, 26004 Logroño, Spain; julio.blanco@unirioja.es \\ * Correspondence: al164438@alumnos.uacj.mx; Tel.: +52-656-688-4841
}

Received: 10 April 2018; Accepted: 28 May 2018; Published: 30 May 2018

check for updates

\begin{abstract}
The aim of this study is to quantify the impact of information and communication technologies (ICT) and its technological updates on the success of the green supply chain (GSC) implementation, as well as the benefits this affords. This research is applied to the Mexican maquiladora export industry. A model of structural equations is presented to know the importance of the integration of ICT, combined with the implementation of GSC and the generation of benefits with the use of ICT. The results indicate that there is a direct, positive effect (PE) and significant among the four latent variables (LTV) analyzed but the most noteworthy is the indirect effect that the variable updating the ICT has on the benefits of GSC, through the variable mediators' implementation of a GSC, since the direct effect of updating the ICT on the benefits of the implementation of GSC does not become significant. Whereby, it is recommended that the industry integrates and updates its ICT since, using the integrated and updated ICT and the implementation of a GSC, a series of economic, productive and environmental benefits will be created.
\end{abstract}

Keywords: information and communication technologies; green supply chain; update and sustainable

\section{Introduction}

Nowadays, organizations must always ensure they consider their environmental impact. Not doing so makes their business outsiders, as the concepts of environmental and social sustainability are becoming increasingly popular amongst organizations, providers, distributors and clients. Adopting a more respectful approach to the environment is now an obligation, not a choice [1]. Organizations develop diverse business strategies but the important and most widely-used is that of the green supply chain (GSC) [2]. GSCs allow a balance between ecological, financial and social benefits, as well as provide a solution to environmental problems and image generated by the different activities which make up the traditional supply chain (SC) [3].

A GSC is a coupling of environmental thinking and traditional SC management [4], which involves several phases in the life of a product: design, selection and material supply, manufacturing processes, integrating information communication technology (ICT), delivering the final product to the consumer and its evaluation at the end of its life-cycle [5,6]. That is, the GSC is the generation of green purchases, green manufacturing, green packaging, the adoption of green technology, green distribution and green marketing, what it is being looked for, trying to eliminate or minimize waste in the form of hazardous, 
chemical, energy, emission and solid waste [6-8]. By adopting a GSC, companies improve their image and social acceptance and they generate higher financial income and so forth.

However, implementing a GSC is no easy task, because it requires a flexible, agile, robust and sustainable design, with long-term results for its procedures, products and green logistics systems [2]. To facilitate the GSC implementation process, companies are integrating ICT into their SC $[9,10]$.

In this context, the use of ICT in the implementation of a GSC requires: the development of information systems, manufacturing which is service focused, intelligent products, robust product testing, environmental intelligence, optimization, energy awareness and auto-organized systems for environmental monitoring [11]. These technologies were inconceivable in the past but have currently helped to provide versatile solutions to the challenges faced in a GSC [12].

All the above shows a tendency towards 'green' supply chains and the implementation of ICT has been a great help in speeding up this process and in obtaining the benefits that that philosophy offers [13]. Therefore, the aim of this study is to quantify the effect ICT and its technological updates has on the success of the implementation of a GSC, as well as the benefits this affords. The results obtained from this research will allow the people responsible for SCs to identify the importance of ICT in the successful implementation of the GSC philosophy and its benefits. It will also make possible the identification of important aspects of those that are trivial in the functioning of GSCs.

\section{Hypotheses and Literature Review}

\subsection{Integrating and Updating ICT in a GSC}

ICTs are technologies which were originally meant to support the exchange of information but in modern-day life ICTs are playing an increasingly important role in our day to day life as humans [14]. Said activities include collating, processing, storing and exchanging information quickly and easily, as well as offering alternative methods in which to work, improving supply chains, controlling transport, energy supply and so forth [15]. In fact, these examples are widely used in predictions about our future, as there are more and more activities which involve more efficient communication and collaboration systems. ICTs have a role to play within the production process, financial management, the relationship with providers, clients and they are considered a vital source of competitiveness and innovation in sustainable industrial systems $[12,16]$.

One of the main advantages offered by ICT in SCs is the exchange of information (EI) in real time and proper form, via the use of intelligent communication networks, such as internet, intranet, Enterprise Resource Planning (ERP), Customer Relationship Management (CRM) and others. Another benefit is that they are used by all members of the SC and can improve the efficiency and the number of eco-friendly practices as well as reduce costs and the need for inventories [11]. ICT has radically and efficiently transformed a great deal of production and transport processes. It allows for the virtualization of products, the digitalization of information, the de-materialization of transport and a reduction in storage space [17].

There are many studies which state that the EI increases the level of service and reduces the time involved in a GSC cycle. All of this affects general expenses, chain inventories, transport and storage costs [11]. It also makes it possible to improve the strategic order of the SC components, feedback and exchange of information in real-time with clients and providers. This means that predictions for demand and production planning are more real and precise.

Besides, the application of updating ICT of a high technological update is considered a powerful tool in the improvement of companies. It allows for an improvement in energy efficiency and EI in many financial sectors. ICT currently provides efficient technical support for environmental monitoring in real time, the management of natural resources and emissions evaluations. The way in which ICT is applied has evolved and makes it possible to reach the environmental objectives of a GSC, whilst also creating value for the market, as well as being a competitive advantage [18]. Not all ICTs have the same benefits however and it all depends on how up-to-date and innovative they are. The impact of ICT 
is reflected in two ways: ecological product innovation (which provides clients with new ecological products) and innovation in ecological procedures (green production process) [19]. Having taken the above into consideration, we suggest the next hypothesis:

Hypothesis 1. $\left(\mathbf{H}_{\mathbf{1}}\right)$ The integration of ICT has a direct and positive effect on updating ICT within a GSC.

\subsection{The Implementation of GSC}

A GSC is a network made up of providers, producers, storage facilities and distributors who work together to turn their plans, activities and raw material into a final product. This SC must also include an environmental outlook across all stages [20]. When it comes to implementing a GSC, the use of ICT is important to try and improve the sustainability of the company's communication, provisioning and transport systems, all of which allows for client and provider involvement (external part of the company's business). This coordination via ICT means that procedures, products and communication via the EI can be better integrated, whilst also minimizing the cost and environmental impact.

A successful implementation of ecological ICTs also contributes to the correct implementation of the GSC. Costs are reduced, relationships between members are improved, the flow of materials increases, deliveries are faster, client satisfaction improves and, what is most important, an environmentally-friendly outlook is reinforced across the entire SC [21]. By implementing the GSC, the use of a unified system and a centralized control system such as ICT, companies improve their inverse logistics with the design of ecological products and procedures. With the aim of determining whether the integration of ICTs facilitates the implementation of a GSC, we suggest the next hypothesis:

Hypothesis 2. $\left(\mathbf{H}_{\mathbf{2}}\right)$ The integration of ICT has a direct and positive effect on the implementation of GSC.

By implementing a GSC, organizations can minimize and eliminate the negative effects that a $\mathrm{SC}$ has on the environment, as well as improve the company's technological or innovative standards. Similarly, ICT must have a positive impact on the environment and produce a PE on the design and processes of eco-products [5]. In order to innovate the GSC technologically the organization must invest in updating of ICT which is able to design products ecologically and monitor production and distribution systems [22], taking into account the fact that these could become obsolete in a very short period of time.

Investment in ICT is currently linked to business growth as well as to the growth of the world's economy [23]. There are specific cases that compare the benefits and productivity obtained by companies of different technological updates (with different levels of up-to-datedness) and those using recently created technologies show a clear advantage $[24,25]$. Considering that how up-to-date the ICT that an organization uses, as well as its technological updates, have a role to play in company operations and their $\mathrm{SC}$, we suggest the next hypothesis:

Hypothesis 3. $\left(\mathbf{H}_{3}\right)$ Updating of ICT has a direct and positive effect on the implementation of GSC.

\subsection{Benefits of the Implementation of GSC}

In a GSC implementation, ICTs have been identified as one of the main forces when it comes to facilitating the process of obtaining social, economic and operative benefits [26]. Nevertheless, we must not forget that the aim of a GSC must be to subject all of an organizations' activities to strict environmental demands and technological innovations in its processes and products, with the objective of maximizing the growth of its income, investment and corporate image [21].

As above mentioned, one of ICT's most valuable resources is EI, as it facilitates a whole list of benefits. These include products which are better adjusted to consumer demand, a reduced need for inventories, the ability to anticipate market changes to reduce transport and increase sales, the ability to respond quickly and detect problems in their early stages to reduce any losses and so forth [24,27]. 
A successful EI shows three potential advantages for producers: a reduction in costs, a reduction in inventory and a reduction in their environmental impact [28]. Partners and participants in the implementation project can benefit from: changing their existing plans, formulating future operations, improving their efficiency, reducing transport, reducing environmental costs and improving their customer service. Having taken the above into consideration, the following hypothesis is proposed:

Hypothesis 4. $\left(\mathbf{H}_{4}\right)$ The integration of ICT has a direct and positive effect when it comes to obtaining benefits from the GSC when it is implemented.

Updating of ICT and a good general technological standard allow for a fast and easy EI between the GSC components, integrating both internal and external business functions [6]. The return on investment also increases thanks to innovation in procedures, as do sales. The EI and ICTs have served to demonstrate the importance of SCs, GSCs and updating of ICTs has also been identified as a key factor in order to achieve environmental sustainability as they facilitate: information line-up and planning, organizational environmental practices, the capacity to improve and allow for an effective compliance with environmental requirements [26]. Having taken the above into consideration, the following hypothesis is proposed:

Hypothesis 5. $\left.\mathbf{( H}_{\mathbf{5}}\right)$ Updating of ICT has a direct and positive effect when it comes to obtaining benefits from the GSC once implemented.

Implementing a GSC in an organization entails a series of benefits, as this process is crucial to promote green-thinking within an organization. Organizations currently have to maintain adequate levels of competitiveness whilst also following government, environmental and social requirements $[29,30]$. Compliance with these types of regulations is essential when it comes to carrying out proactive ecological strategies, needed to achieve environmental goals and an improved business image. To successfully implement a GSC, however, it is fundamental that providers and customers take an active part [31,32]. Solid partnerships with providers and customers help in the adoption and development of innovative and environmentally-friendly technologies. Having taken the above into consideration, the next hypothesis is proposed:

Hypothesis $\left.\mathbf{6} . \mathbf{H}_{\mathbf{6}}\right)$ The implementation of GSC has a direct and positive effect when it comes to obtaining benefits from the GSC when it is implemented.

Figure 1 shows the association between the variables analyzed in this study; it indicates the number of items in each, which is discussed in the Methodology section of this manuscript.

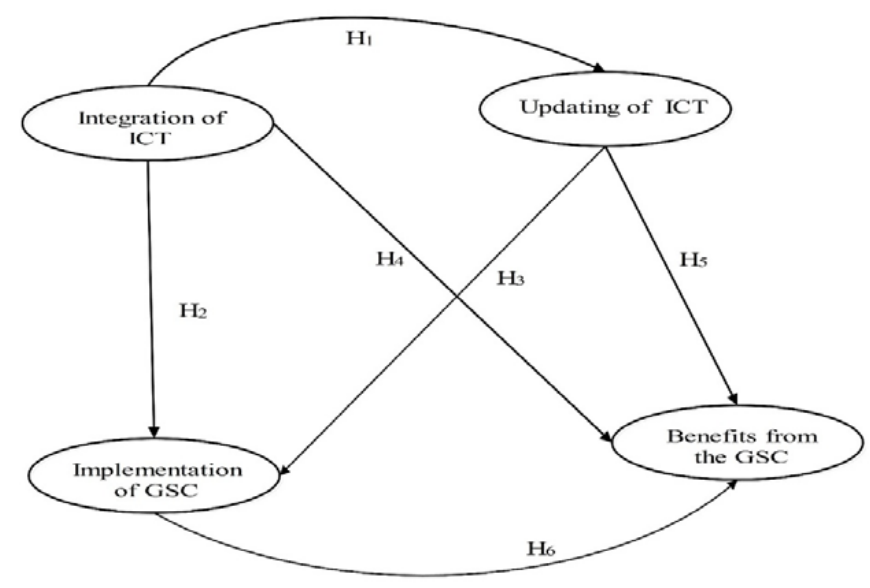

Figure 1. Hypothesis. 


\section{Development of Methodology}

\subsection{Phase 1. Sample Collection}

To collect information and validate the model in Figure 1, a designed questionnaire has been used, one of the most used methods to gather information easily and quickly [33-35], as well as a deep revision of literature, which allows us to identify research related to the integration and updating of IT, the implementation and the benefits of a GSC, all considered LTV. The literature revisions a rational validation of the questionnaire and identifies the items.

Given that the questionnaire items were obtained from research carried out in different countries and industrial sectors, a group of green supply chain experts, including academics and engineers working in companies, evaluated the congruence, relevance, importance and language. This process represents a judges' validation and helped to adapt it to the context of the maquiladora industry [36,37].

The final questionnaire is divided into two parts. The first part is composed of twelve LTV, of which only four were taken to develop this research, defined as the LTV in Figure 1 and the items appear in Table 1. The items were responded to on a Likert scale with values of one to five, where one indicates very low or never and five indicates very high or always. The second section is a series of demographic questions such as the respondent's position, years of experience and so forth, which will help us characterize the sample.

Table 1. Items in the LTV.

\begin{tabular}{|c|c|}
\hline Integration of ICT & Acronym \\
\hline Use of ERP, CRM and Intranet with providers $[12,19]$ & ITI1 \\
\hline EI is used in real-time with providers $[11,19]$ & ITI2 \\
\hline There is an improved ICT line-up with providers $[11,17]$ & ITI3 \\
\hline Use of EI across the entire organization $[11,18]$ & ITI4 \\
\hline Use of ERP, CRM and Intranet with clients $[12,19]$ & ITI5 \\
\hline Use of EI via ICT with clients $[11,38]$ & ITI6 \\
\hline Improved ICT line-up with intelligent products $[12,38]$ & ITI7 \\
\hline Feedback across all levels via ICT $[18,19]$ & ITI8 \\
\hline Use of ICT in predictions with providers $[11,17]$ & ITI9 \\
\hline \multicolumn{2}{|l|}{ Updating of ICT } \\
\hline Use of the most up-to-date ecological ICTs $[17,18]$ & UTI1 \\
\hline More modern ICT than the competitors $[12,19]$ & UTI2 \\
\hline Investment in ICT to align their technology with that of its partners $[12,19]$ & UTI3 \\
\hline \multicolumn{2}{|l|}{ Implementation of GSC } \\
\hline Work on the product's life cycle (inverse logistics) [32,39] & IGSC1 \\
\hline GSC is considered a priority strategy $[16,26]$ & IGSC2 \\
\hline Implement indicators to measure environmental impact $[18,40]$ & IGSC3 \\
\hline Green initiatives are backed by superior management $[39,40]$ & IGSC4 \\
\hline $\begin{array}{l}\text { Savings are generated because of the GSC in energy, transport, storage and } \\
\text { packaging }[11,18]\end{array}$ & IGSC5 \\
\hline $\begin{array}{l}\text { The company's performance is better than its competitors when it comes to } \\
\text { managing the GSC }[8,41]\end{array}$ & IGSC6 \\
\hline Environmentally-friendly products are designed $[5,16]$ & IGSC7 \\
\hline $\begin{array}{l}\text { Green initiatives are invested in even if they do not generate a return on } \\
\text { investment (ROI) }[8,42]\end{array}$ & IGSC8 \\
\hline Green initiatives are evaluated over the entire SC $[17,39]$ & IGSC9 \\
\hline \multicolumn{2}{|l|}{ Benefits from the GSC } \\
\hline Reduced costs $[9,11]$ & BGSC1 \\
\hline Increased sales $[5,42]$ & BGSC2 \\
\hline Customer satisfaction $[26,43]$ & BGSC3 \\
\hline Better ROI $[5,11]$ & BGSC4 \\
\hline Increase in income $[8,42]$ & BGSC5 \\
\hline Reduction in emissions/waste $[11,40]$ & BGSC6 \\
\hline Improved business image $[5,26]$ & BGSC7 \\
\hline Increase income through ecological products $[5,16]$ & BGSC8 \\
\hline Product innovation $[40,41]$ & BGSC9 \\
\hline
\end{tabular}


The questionnaire is applied to the Mexican Maquiladora export industry, focusing on staff with at least one-years' experience on their job, so that the sampling is stratified into different categories. We set up appointments with managers to apply the questionnaire in a personal interview and the respondents later recommended the questionnaire to their colleagues and then a snowball sampling followed.

\subsection{Phase 2. Capture and Debugging the Sample}

The information is processed using statistic software called SPSS $24^{\circledR}$ and data is de-bugged with the aim of detecting atypical values and any missing values. These are replaced by the value of the median for each item due to its ordinal values [44]. In addition, we calculate the standard deviation in each case of the questionnaires applied to identify respondents who are not committed, where cases of values of lower than 0.500 on the standard deviation are eliminated [45].

\subsection{Phase 3. Definition of $L T V$}

Although the LTV in the questionnaire had already defined a list of items that integrated them, to demonstrate statistically that there was an association between the dimension and the items, a factorial analysis of the four variables analyzed was developed. A promax rotation is used to continue with the analysis of structural equations models and the factorial loads and the associated $p$-values of each item are analyzed. In this case, it is sought that the factorial loads are greater than 0.5 and that the $p$ associated value is less than $0.05[46,47]$.

\subsection{Phase 4. Characterization of the Items}

We carry out a characterization of the items which make up every of the LTV. We use the interquartile range (IR) as a measure of dispersion of the data, so the first and third quartile of data is calculated. High values specify that there is no consensus between the respondents in relation to the true value that that item should have but if the value is low, it specifies a consensus on its value [48]. The median is also used as a measure of central tendency and high values indicate that the respondents consider that item to be very important, while low values specify that the item is not very important to them [49].

\subsection{Phase 5. Characterization of the Sample}

Crossed tables are used for analysis on demographic data. These tables will serve to characterize the sample in terms of the gender of responders, the industrial sector to which they belong, the years of experience and the job position. These tables help to determine the level of experience that the respondents had and, therefore, the reliability of the information obtained, as well as to identify tendencies in responders.

\subsection{Phase 6. Statistical Validation}

For the statistical validation for the LTV in the model, we have used different indices, such as:

1. Average Variance Extracted (AVE) to determine the convergent validity, for which values of over 0.5 were expected [50].

2. Cronbach's Alpha and the reliability index to determine the reliability on the scale and values of over 0.7 are expected [51].

3. Full collinearity VIF to identify vertical and lateral collinearity, for which values lower than 5 are expected [52].

4. R-squared and R-squared adjusted to measure parametric predictive validity.

5. Q-squared to measure non-parametric predictive validity [52]. 


\subsection{Phase 7. Design of Structural Equations Modelling}

The model in Figure 1 is assessed by means of structural equations based on partial least squares (PLS), a multi-variate analysis technique used and applied in diverse research areas for example biology, medicine and engineering [53]. The software used to simulate the model is WarpPLS $5.0^{\circledR}$, the algorithms of which are based on PLS and the use of which is recommended in small samples, unusual data or data obtained by means of a Likert scale [54].

Several efficiency indices are analyzed before the model interpretation, for example: average path coefficient (APC) to test the hypotheses, the average R-squared (ARS), average adjusted R-squared (AARS) for predictive validity, average variance inflation factor (AVIF) and average full collinearity VIF (AFVIF) for collinearity and the Tenenhaus GoF for data fit. The study established 0.05 as a maximum cut-off $p$-value for these indices; thus, inferences were made with a $95 \%$ confidence level, testing the null hypothesis that APC and ARS are equal to zero, versus the alternative hypothesis stating that $\mathrm{APC}$ and ARS are different to zero.

Three different types of effects are analyzed in the model; (1) direct effects (appearing in Figure 1 as arrows from an LTV to other); (2) indirect effects (given by paths with two or more segments); and (3) total effects (the sum of direct and indirect effects). Also, in order to determine their significance, the $p$-values were analyzed by comparing the null hypothesis $\beta \mathrm{i}=0$, versus the alternative hypothesis $\beta i \neq 0[55]$.

\section{Results}

\subsection{Descriptive Analysis of the Sample}

The survey is applied for 6 months and 326 questionnaires were obtained, of which only 284 were valid for the analysis after performing the debugging of the database, where 42 were eliminated because they contained missing data or uninvolved respondents were detected. Table 2 shows the crossed table, which compares the industrial sector and gender of the interviewees; first, it is observed that there was more participation from men than women, with a total participation of 194 men, who represent the $68.30 \%$ of the total sample and only 90 women, representing $31.69 \%$. Likewise, it can be observed that $198(69.71 \%)$ of the interviewees are from the two industrial sectors, 119 belonging to the automotive sector and 79 to the electrical/electronic sector.

Table 2. Industrial sector and gender.

\begin{tabular}{cccc}
\hline \multirow{2}{*}{ Sector } & \multicolumn{2}{c}{ Gender } & \multirow{2}{*}{ Total } \\
\cline { 2 - 3 } & Male & Female & \\
\hline Automotive & 77 & 42 & 119 \\
Electric/Electronic & 56 & 23 & 79 \\
Other & 15 & 8 & 23 \\
Medical & 13 & 6 & 19 \\
Metalworking & 13 & 3 & 16 \\
Plastics & 9 & 2 & 11 \\
Communications & 6 & 2 & 8 \\
Textile & 3 & 2 & 5 \\
Services & 2 & 2 & 4 \\
Total & 194 & 90 & 284 \\
\hline
\end{tabular}

Table 3 shows the crossed table, which compares the position of the interviewees and their years of experience. It can be seen that 213 of the interviewees have a high hierarchical position, 139 are engineers and 74 are managers. Table 3 also indicates that 242 interviewees, that is $85.21 \%$, have more than two years of experience in their position, which will help us validate the information obtained based on the experience of the interviewees. 
Table 3. Job position and years of experience.

\begin{tabular}{|c|c|c|c|c|c|c|}
\hline \multirow{2}{*}{ Job Position } & \multicolumn{5}{|c|}{ Years of Experience } & \multirow{2}{*}{ Total } \\
\hline & $>1-<2$ & $>2-<3$ & $>3-<4$ & $>4-<5$ & $>5$ & \\
\hline Engineer & 12 & 23 & 18 & 36 & 56 & 139 \\
\hline Manager & 2 & 4 & 11 & 22 & 35 & 74 \\
\hline Storekeeper & 4 & 5 & 6 & 10 & 18 & 43 \\
\hline Technician & 13 & 2 & 7 & 4 & 2 & 28 \\
\hline Total & 42 & 51 & 31 & 25 & 135 & 284 \\
\hline
\end{tabular}

\subsection{LTV Generation}

Table 4 illustrates the factorial analysis for the 30 items analyzed in the four latents. The factor loading of each item in all the LTV is illustrated and in the last column appears the $p$ value for the statistical test of significance. Given that the factorial loads are greater than 0.5 in all the items and that the $p$ value is less than 0.001 , it is concluded that all the items have convergent validity in the variable that has initially been proposed, allowing to proceed to the model analysis.

Table 4. Factor loadings.

\begin{tabular}{|c|c|c|c|c|c|}
\hline \multirow{2}{*}{ Items } & \multicolumn{4}{|c|}{ LTV } & \multirow{2}{*}{$p$-Value } \\
\hline & Integration of ICT & Updating of ICT & Implementation of GSC & Benefits from the GSC & \\
\hline ITI1 & 0.759 & 0.058 & -0.141 & 0.134 & $<0.001$ \\
\hline ITI7 & 0.8 & -0.063 & -0.035 & -0.01 & $<0.001$ \\
\hline ITI8 & 0.809 & 0.188 & 0.007 & -0.003 & $<0.001$ \\
\hline ITI9 & 0.74 & 0.095 & 0.016 & 0.022 & $<0.001$ \\
\hline ITI2 & 0.773 & -0.029 & -0.105 & 0.081 & $<0.001$ \\
\hline ITI3 & 0.806 & 0.002 & 0.157 & -0.072 & $<0.001$ \\
\hline ITI4 & 0.763 & -0.051 & 0.088 & -0.096 & $<0.001$ \\
\hline ITI5 & 0.808 & -0.051 & -0.011 & -0.012 & $<0.001$ \\
\hline ITI6 & 0.818 & -0.141 & 0.015 & -0.036 & $<0.001$ \\
\hline UTI1 & -0.02 & 0.91 & -0.066 & 0.056 & $<0.001$ \\
\hline UTI2 & 0.051 & 0.922 & 0.075 & -0.071 & $<0.001$ \\
\hline UTI3 & -0.031 & 0.922 & -0.01 & 0.016 & $<0.001$ \\
\hline IGSC2 & -0.141 & 0.191 & 0.856 & -0.018 & $<0.001$ \\
\hline IGSC4 & -0.039 & 0.04 & 0.885 & -0.039 & $<0.001$ \\
\hline IGSC6 & 0.065 & -0.035 & 0.905 & -0.034 & $<0.001$ \\
\hline IGSC7 & 0.087 & -0.131 & 0.875 & 0.033 & $<0.001$ \\
\hline IGSC1 & 0.062 & -0.06 & 0.825 & -0.105 & $<0.001$ \\
\hline IGSC3 & -0.014 & -0.004 & 0.866 & 0.043 & $<0.001$ \\
\hline IGSC5 & -0.044 & -0.002 & 0.84 & 0.139 & $<0.001$ \\
\hline IGSC8 & 0.142 & -0.207 & 0.869 & 0.023 & $<0.001$ \\
\hline IGSC9 & -0.125 & 0.217 & 0.838 & -0.042 & $<0.001$ \\
\hline BGSC9 & -0.065 & 0.061 & 0.024 & 0.844 & $<0.001$ \\
\hline BGSC1 & 0.068 & -0.044 & -0.184 & 0.844 & $<0.001$ \\
\hline BGSC7 & -0.106 & 0.05 & 0.048 & 0.831 & $<0.001$ \\
\hline BGSC5 & -0.062 & 0.004 & -0.185 & 0.854 & $<0.001$ \\
\hline BGSC8 & -0.063 & -0.024 & 0.043 & 0.808 & $<0.001$ \\
\hline BGSC4 & 0.064 & -0.011 & 0.046 & 0.835 & $<0.001$ \\
\hline BGSC6 & -0.013 & 0.115 & 0.186 & 0.852 & $<0.001$ \\
\hline BGSC2 & -0.012 & 0.06 & -0.089 & 0.817 & $<0.001$ \\
\hline BGSC3 & 0.196 & -0.222 & 0.116 & 0.801 & $<0.001$ \\
\hline
\end{tabular}

\subsection{Characterization of the Items}

The descriptive analysis of the items appears in Table 5 and is shown in descending order in accordance with the median value from the second column. We can see that 29 out of the total 30 items have a median greater than 4 , which means that, according to the participants' perception, these items are the most significant and the ones they associate the most with the Integration of ICT, Updating of ICT 
and the GSC and that they can come to have a greater impact on their implementation. Finally, in the third column we can see the IR as a measure of dispersion.

Table 5. Characterization of the items.

\begin{tabular}{|c|c|c|}
\hline Items Integration of ICT & Median & IR \\
\hline ITI1 & 4.788 & 1.971 \\
\hline ITI5 & 4.607 & 2.003 \\
\hline ITI7 & 4.485 & 1.959 \\
\hline ITI9 & 4.470 & 2.093 \\
\hline ITI2 & 4.467 & 1.953 \\
\hline ITI8 & 4.396 & 1.979 \\
\hline ITI3 & 4.364 & 2.006 \\
\hline ITI6 & 4.273 & 2.024 \\
\hline ITI4 & 4.272 & 2.119 \\
\hline \multicolumn{3}{|c|}{ Updating of ICT } \\
\hline UTI3 & 4.364 & 2.076 \\
\hline UTI1 & 4.327 & 2.075 \\
\hline UTI2 & 4.268 & 2.055 \\
\hline \multicolumn{3}{|c|}{ Implementation of GSC } \\
\hline IGSC3 & 4.361 & 2.040 \\
\hline IGSC7 & 4.318 & 2.094 \\
\hline IGSC5 & 4.307 & 2.211 \\
\hline IGSC9 & 4.207 & 2.128 \\
\hline IGSC1 & 4.187 & 2.027 \\
\hline IGSC6 & 4.169 & 1.983 \\
\hline IGSC2 & 4.131 & 2.039 \\
\hline IGSC4 & 4.056 & 2.066 \\
\hline IGSC8 & 3.961 & 2.194 \\
\hline \multicolumn{3}{|c|}{ Benefits from the GSC } \\
\hline BGSC2 & 4.865 & 1.762 \\
\hline BGSC1 & 4.702 & 1.972 \\
\hline BGSC7 & 4.700 & 2.019 \\
\hline BGSC6 & 4.664 & 2.025 \\
\hline BGSC9 & 4.625 & 2.003 \\
\hline BGSC4 & 4.497 & 2.011 \\
\hline BGSC5 & 4.483 & 2.107 \\
\hline BGSC8 & 4.322 & 2.096 \\
\hline BGSC3 & 4.136 & 1.659 \\
\hline
\end{tabular}

\subsection{Validation of $L T V$}

The indices for validating LTV integrated in the model in Figure 1 appear in Table 6 . We can see that the coefficients R-squared, adjusted R-squared and Q-squared are presented only for dependent LTV and that the values mentioned above are acceptable, as they are greater than 0.02 , which means that the model has an adequate predictive validity (parametric and non-parametric). Similarly, the average variance extracted (AVE) is shown. We can see that all the LTV have values close to, or greater than 0.5 , which specifies that the model has an acceptable convergent validity.

The reliability index and the Cronbach's Alpha coefficients are calculated for all LTV and it is observed that those values are greater than 0.7 , so it is concluded that the LTV have an internal validity. Finally, we observe that all the LTV analyzed have a VIF value lower than 3.3, which specifies that there are no collinearity issues. 
Table 6. Validation of LTV.

\begin{tabular}{ccccc}
\hline LTV Coefficients & Integration of ICT & Updating of ICT & Implementation of GSC & Benefits from the GSC \\
\hline R-squared & & 0.526 & 0.412 & 0.599 \\
Adj. R-squared & & 0.524 & 0.408 & 0.595 \\
Q-squared & & 0.526 & 0.414 & 0.600 \\
Avg. var. extract. & 0.619 & 0.843 & 0.744 & 0.692 \\
Cronbach's alpha & 0.923 & 0.907 & 0.957 & 0.944 \\
Composite reliab. & 0.936 & 0.942 & 0.963 & 0.953 \\
Full collin. VIF & 2.358 & 2.475 & 2.457 & 2.463 \\
\hline
\end{tabular}

\subsection{Structural Equations Model}

The model's results are shown in Figure 2, where each segment shows the association between two LTV and is shown using the $\beta$ parameter and the p-value, while R-squared is used to measure the variance quantity explained in dependent variables, as well as indicating the combined loadings and the cross-loadings to determine the convergent validity of each of the items.

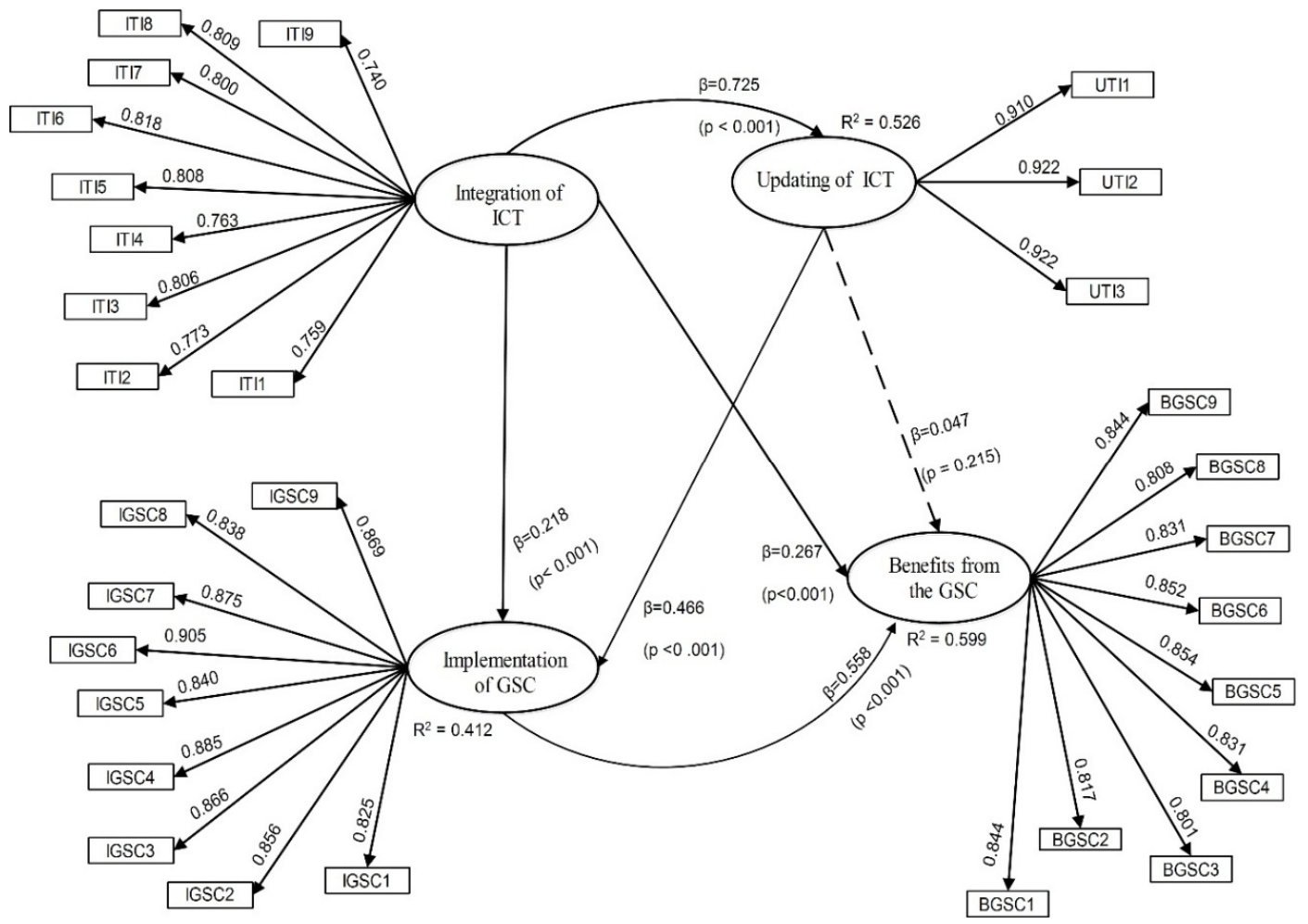

Figure 2. Model developed.

The efficiency indices obtained for the model are as follows and as it can be observed, they all meet the cut-off values established:

- $\quad$ Average path coefficient $(\mathrm{APC})=0.380, p<0.001$

- $\quad$ Average R-squared (ARS) $=0.512, p<0.001$

- $\quad$ Average adjusted R-squared (AARS) $=0.509, p<0.001$

- $\quad$ Average block VIF (AVIF) $=2.110$, acceptable if $\leq 5$, ideally $\leq 3.3$

- $\quad$ Average full collinearity VIF $(\mathrm{AFVIF})=2.438$, acceptable if $\leq 5$, ideally $\leq 3.3$

- $\quad$ Tenenhaus GoF $(\mathrm{GoF})=0.609$, small $\geq 0.1$, medium $\geq 0.25$, large $\geq 0.36$

According to values in Figure 2, the structural equations obtained of the model are presented below: 
- Updating of ICT $=0.725$ Integration of ICT + Error

- Implementation of GCS $=0.218$ Integration of ICT +0.466 Updating of ICT + Error

- Benefits from the GSC $=0.558$ Implementation of GSC + 0.267 Integration of ICT + 0.047 Updating of ICT + Error

\subsubsection{Direct Effects in the Model}

Figure 1 displays the hypothesis considered in the initial model, the direct effects of this are illustrated in Figure 2 and this is used as a basis for the following conclusions:

$\mathrm{H}_{1}$ : There is necessary statistical certainty to say that the Integration of ICT has a direct and PE on the Updating of ICT within a GSC, since when the first LTV increases its standard deviation by one unit, the second does so by 0.725 units.

$\mathbf{H}_{2}$ : There is necessary statistical certainty to say that the Integration of ICT has a direct and PE on the Implementation of GSC since when the first LVT increases its standard deviation by one unit, the second does so by 0.218 units.

$\mathbf{H}_{3}$ : There is necessary statistical certainty to say that Updating of ICT has a direct and PE on the Implementation of a GSC since when the first LTV increases its standard deviation by one unit, the second does so by 0.466 units.

$\mathbf{H}_{4}$ : There is necessary statistical certainty to say that the Integration of ICT has a direct and PE when it comes to obtaining the Benefits from the GSC with its implementation, since when the first LTV increases its standard deviation by one unit, the second does so by 0.267 units.

$\mathbf{H}_{5}$ : There is not necessary statistical certainty to say that Updating of ICT has a direct and PE when it comes to obtaining the Benefits from the GSC with its implementation; this is stated with a $95 \%$ confidence level, as the associated p-value is greater than 0.05 .

$\mathbf{H}_{6}$ : There is necessary statistical certainty to say that the Implementation of GSC has a direct and PE when it comes to obtaining the Benefits from the GSC with its implementation, since when the first LTV increases its standard deviation by one unit, the second does so by 0.558 units.

It is very significant to note the direct effect the LTV of the Benefits from the GSC has and that $59.9 \%$ of the time it can be explained by the variables Integration of ICT, Updating of ICT and Implementation of GSC. Its R squared has a value of $0.599,16.2 \%$ of which stems from the variable Integration of ICT, $2.7 \%$ from the variable Updating of ICT and $41 \%$ from the LTV Implementation of a GSC. Using these findings as our base, we can conclude that organizations must prioritize the successful implementation of GSC, since it is what has the greatest impact and explanatory power when it comes to obtaining the Benefits from the GSC.

\subsubsection{Indirect Effects in the Model}

In the model assessed, which is illustrated in Figure 2, can be seen 4 indirect effects, defined as follows:

1. The LTV entitled Integration of ICT has an indirect two-segment impact on the LTV entitled Implementation of GSC, which is a result of the measurement variable Updating of ICT. Whereby, the indirect effect is of $0.338(p<0.001)$, which is statistically significant and can explain up to $18.8 \%$ of its variability.

2. The LTV entitled Integration of ICT has an indirect two-segment impact on the LTV entitled Benefits from the GSC, which comes about through the measurement variable Updating of ICT and Implementation of a GSC. Whereby, the indirect effect is of $0.155(p<0.004)$, which is statistically significant and can explain up to $9.4 \%$ of its variability. 
3. The LTV entitled Integration of ICT has an indirect three-segment impact on the LTV entitled Benefits from the GSC, which comes about through the measurement variable Updating of ICT and measurement variable Implementation of GSC. In this case, the indirect effect is of $0.189(p<0.001)$, which is statistically significant and can explain up to $11.5 \%$ of its variability.

4. The LTV entitled Updating of ICT has an indirect two-segment impact on the LTV entitled Benefits from the GSC, which comes about through the measurement variable Implementation of GSC. Whereby, the indirect effect is of $0.260(p<0.001)$, which is statistically significant and can explain up to $15.2 \%$ of its variability.

Table 7 shows the sum of the total indirect effects-the sum of the effects of two and three segments which exist between the variables in the projected in Figure 1.

Table 7. Sum of Indirect Effects.

\begin{tabular}{ccc}
\hline \multirow{2}{*}{ To } & \multicolumn{2}{c}{ From } \\
\cline { 2 - 3 } & Integration of ICT & Updating of ICT \\
\hline \multirow{2}{*}{ Implementation of GSC } & $0.338(p<0.001)$ & \\
& $\mathrm{ES}=0.188$ & $0.260(p<0.001)$ \\
Benefits from the GSC & $0.334(p<0.001)$ & $\mathrm{ES}=0.152$ \\
\hline
\end{tabular}

\subsubsection{Total Effects in the Model}

The totality of the indirect and direct effects affords the total effects, which are shown in Table 8. It is noteworthy that in three variables the direct effect is the same as the total effect, which indicates that there is no indirect effect and in the other three the sum of the direct and indirect effects is included. It is vital to note that the direct effect of Updating of ICT with the variable Benefits from the GSC is only 0.047 and that it was not significant with a 95\% confidence level. The indirect effect via the variables of Updating of ICT and the variable Benefits of GSC is of 0.260; in other words, the indirect effect is much greater and more significant than the direct effect, which shows that a company must make sure they have all the most updating ICT equipment. This also becomes an advantage when it comes to the implementation and management of a GSC and are the only way to obtain its benefits.

Table 8. Total Effects.

\begin{tabular}{cccc}
\hline \multirow{2}{*}{ To } & \multicolumn{3}{c}{ From } \\
\cline { 2 - 4 } & Integration of ICT & Updating of ICT & Implementation of GSC \\
\hline \multirow{2}{*}{ Updating of ICT } & $0.725(p<0.001)$ & & \\
& $\mathrm{ES}=0.526$ & & \\
\hline \multirow{2}{*}{ Implementation of GSC } & $0.556(p<0.001)$ & $0.466(p<0.001)$ & \\
& $\mathrm{ES}=0.309$ & $\mathrm{ES}=0.291$ & $0.558(p<0.001)$ \\
Benefits from the GSC & $0.611(p<0.001)$ & $0.307(p<0.001)$ & $\mathrm{ES}=0.410$ \\
& $\mathrm{ES}=0.372$ & $\mathrm{ES}=0.179$ & \\
\hline
\end{tabular}

\section{Conclusions and Limitations}

The model proposed and the six hypotheses, were valid with information from the Mexican manufacturing industry but their conclusions can be extended to the rest of this industrial sector in other countries, since in the Mexican manufacturing industry the sector is basically composed of companies from all around the world, such as United States of America, Germany, Japan, France, China and so forth.

Based on the results obtained, it can be observed that the Integration of ICT and Updating of ICT are related. This is because one complements the other, which is validated via $\mathrm{H}_{1}$, as the greatest 
and most significant direct effect in the entire model, since keeping ICTs integrated and updated provides a platform that helps companies to exchange knowledge, align processes and achieve operational flexibility. Furthermore, the integration of ICT affects the efficiency and effectiveness of business processes within and beyond the boundaries of the organization and updated ICTs become an important advantage that is reflected in the efficiency of operations performance [26,56].

Additionally, it is very important to highlight that ICTs constitute an effective tool, which facilitates the implementation of a GSC. The above statement is proven through the total and significant effect, which the LTV Integration of ICTs has on the variable Implementation of a GSC. In addition to that, Gunasekaran, et al. [57] mention the importance of involving ICT in the implementation of GSC, since this allows the collaboration and exchange of data and information, generating agility in decision making. Besides, Lee, Ooi, Chong and Seow [22] mention that having ICT integrated and updated through a GSC, a series of financial, productive and environmental benefits are created only if the companies see the adoption and implementation of the GSC as an advantage.

Using ICTs of a high technological standard in the implementation and management of a GSC is a strategic priority [26]; these ICTs generate benefits for the supply chain in the long-term. It is important to recognize, however, that those benefits can only be obtained through the Implementation of a successful GSC, as it is the measurement variable in this case. This shows that the ICT is only important when applied to an ecological SC, and, according to Marinagi, et al. [58], the development of current ICT systems for GSC supports and accelerates all commercial activities, improving decision making and productivity, and, according to Marinagi, Trivellas and Sakas [20], can generate a competitive advantage throughout the SC.

The analysis of the relationship between the Implementation of ICTs in the Benefits from the GSC is also important. The direct effect was just 0.267 (see Figure 2) but the indirect effect was of 0.334, achieved through Updating of ICT and the Implementation of the GSC as mediator variables. The above shows the importance of ICTs but only if they are up-to-date and applied to green supply chains, as on their own, the benefits are minimal. In this way, there is a total effect between variables of 0.611 , the second greatest observed.

Lastly, it is important to highlight that according to Luthra, Garg and Haleem [32], a GSC generates a series of economic benefits that will be reflected in the reduction of costs of products and processes. For example, social benefits will contribute to the protection of the environment and will create a level of awareness of the clients, which will help to increase the sales and can aid to achieve social performances and competitiveness factors. These benefits help to minimize ecological damage and generate a global economic benefit [59]. This statement is proven by the total and significant effect between the variable Implementation of a GSC and Benefits from the GSC.

The afore-mentioned results indicate that ICT investments must be duly implemented in supply chain and they must be implemented to an adequate technological update which allows for the visibility of the same. In addition, information must be exchanged in real-time (with providers, production system departments and clients) and they must follow all the rules and standards established by the country in which the company is located.

\section{Future Studies}

The success of a GSC depends on many factors and in this study, we have only considered the integration of ICT and its technological update. In future studies we will try to integrate factors associated to the level of education and training that staff have, as a high level of knowledge is needed in order to use these technologies-to reprogram them for other activities and adapt them to different production lines, as is pointed out by Jabbour and de Sousa Jabbour [59]. It is also intended to use the remaining information from the questionnaire to design more structural equations models and to follow up on this research with the association of other LTVs, such as the ICT flexibility. 
Author Contributions: The six authors participated in this manuscript. J.R.M.-F. studied the information and wrote the article. J.L.G.-A. participated in the design and development of the methodology. E.J.M. did the data analysis in the results part. J.B.F. made the questionnaire design and validation. J.R.D.-R. and N.L.I.H. they made the final revision of the document and corrections.

Funding: This research received founding from Autonomous University of Ciudad Juarez under grant UACJ-PIVA 2017-1 JL Garcia.

Acknowledgments: The authors acknowledge to the Mexican National Council for Science and Technology (CONACYT).

Conflicts of Interest: The authors declare that they have no conflict of interest regarding the publication of this paper.

\section{References}

1. Mendoza-Fong, J.R.; García-Alcaraz, J.L.; de Jesús Ochoa-Domínguez, H.; Cortes-Robles, G. Green production attributes and its impact in company's sustainability. In New Perspectives on Applied Industrial Tools and Techniques; García-Alcaraz, J.L., Alor-Hernández, G., Maldonado-Macías, A.A., Sánchez-Ramírez, C., Eds.; Springer International Publishing: Cham, Switzerland, 2017; pp. 23-46.

2. Diabat, A.; Khodaverdi, R.; Olfat, L. An exploration of green supply chain practices and performances in an automotive industry. Int. J. Adv. Manuf. Technol. 2013, 68, 949-961. [CrossRef]

3. Mangla, S.K.; Kumar, P.; Barua, M.K. A flexible decision framework for building risk mitigation strategies in green supply chain using sap-lap and irp approaches. Glob. J. Flex. Syst. Manag. 2014, 15, $203-218$. [CrossRef]

4. Mendoza-Fong, J.; García-Alcaraz, J.; Díaz-Reza, J.; Sáenz Diez Muro, J.; Blanco Fernández, J. The role of green and traditional supplier attributes on business performance. Sustainability 2017, 9, 1520. [CrossRef]

5. Uygun, Ö.; Dede, A. Performance evaluation of green supply chain management using integrated fuzzy multi-criteria decision making techniques. Comput. Ind. Eng. 2016, 102, 502-511. [CrossRef]

6. Centobelli, P.; Cerchione, R.; Esposito, E. Environmental sustainability in the service industry of transportation and logistics service providers: Systematic literature review and research directions. Transp. Res. Part D Transp. Environ. 2017, 53, 454-470. [CrossRef]

7. Jayant, A.; Azhar, M. Analysis of the barriers for implementing green supply chain management (GSCM) practices: An interpretive structural modeling (ISM) approach. Procedia Eng. 2014, 97, 2157-2166. [CrossRef]

8. Chin, T.A.; Tat, H.H.; Sulaiman, Z. Green supply chain management, environmental collaboration and sustainability performance. Procedia CIRP 2015, 26, 695-699. [CrossRef]

9. Lotfi, Z.; Mukhtar, M.; Sahran, S.; Zadeh, A.T. Information sharing in supply chain management. Procedia Technol. 2013, 11, 298-304. [CrossRef]

10. Chugh, R.; Wibowo, S.; Grandhi, S. Environmentally sustainable information and communication technology usage: Awareness and practices of indian information and communication technology professionals. J. Clean. Prod. 2016, 131, 435-446. [CrossRef]

11. Khan, M.; Hussain, M.; Saber, H.M. Information sharing in a sustainable supply chain. Int. J. Prod. Econ. 2016, 181, 208-214. [CrossRef]

12. Trentesaux, D.; Borangiu, T.; Thomas, A. Emerging ICT concepts for smart, safe and sustainable industrial systems. Comput. Ind. 2016, 81, 1-10. [CrossRef]

13. Centobelli, P.; Cerchione, R.; Esposito, E. Developing the wh2 framework for environmental sustainability in logistics service providers: A taxonomy of green initiatives. J. Clean. Prod. 2017, 165, 1063-1077. [CrossRef]

14. Pattinson, C. ICT and green sustainability research and teaching. IFAC-PapersOnLine 2017, 50, 12938-12943. [CrossRef]

15. Neshati, R.; Daim, T.U. Participation in technology standards development: A decision model for the information and communications technology (ICT) industry. J. High Technol. Manag. Res. 2017, 28, 47-60. [CrossRef]

16. Chen, Y.-C.; Chu, C.N.; Sun, H.-M.; Chen, R.-S.; Chen, L.-C.; Chen, C.-C. Application of green collaboration operation on network industry. Int. J. Precis. Eng. Manuf.-Green Technol. 2015, 2, 73-83. [CrossRef]

17. Börjesson Rivera, M.; Håkansson, C.; Svenfelt, Å.; Finnveden, G. Including second order effects in environmental assessments of ICT. Environ. Model. Softw. 2014, 56, 105-115. [CrossRef]

18. Radu, L.-D. Green ICTs potential in emerging economies. Procedia Econ. Financ. 2014, 15, 430-436. [CrossRef] 
19. Klimova, A.; Rondeau, E.; Andersson, K.; Porras, J.; Rybin, A.; Zaslavsky, A. An international master's program in green ICT as a contribution to sustainable development. J. Clean. Prod. 2016, 135, $223-239$. [CrossRef]

20. Marinagi, C.; Trivellas, P.; Sakas, D.P. The impact of information technology on the development of supply chain competitive advantage. Procedia-Soc. Behav. Sci. 2014, 147, 586-591. [CrossRef]

21. Mishra, D.; Gunasekaran, A.; Papadopoulos, T.; Hazen, B. Green supply chain performance measures: A review and bibliometric analysis. Sustain. Prod. Consum. 2017, 10, 85-99. [CrossRef]

22. Lee, V.-H.; Ooi, K.-B.; Chong, A.Y.-L.; Seow, C. Creating technological innovation via green supply chain management: An empirical analysis. Expert Syst. Appl. 2014, 41, 6983-6994. [CrossRef]

23. Jorgenson, D.W.; Vu, K.M. The impact of ICT investment on world economic growth. Telecommun. Policy 2016, 40, 381-382. [CrossRef]

24. Chung, H. ICT investment-specific technological change and productivity growth in Korea: Comparison of 1996-2005 and 2006-2015. Telecommun. Policy 2017, 42, 78-90. [CrossRef]

25. Hong, J. Causal relationship between ICT R\&D investment and economic growth in Korea. Technol. Forecast. Soc. Chang. 2017, 116, 70-75.

26. De Camargo Fiorini, P.; Jabbour, C.J.C. Information systems and sustainable supply chain management towards a more sustainable society: Where we are and where we are going. Int. J. Inf. Manag. 2017, 37, 241-249. [CrossRef]

27. Mensah, P.; Merkuryev, Y.; Longo, F. Using ICT in developing a resilient supply chain strategy. Procedia Comput. Sci. 2015, 43, 101-108. [CrossRef]

28. Lotfi, Z.; Sahran, S.; Mukhtar, M.; Zadeh, A.T. The relationships between supply chain integration and product quality. Procedia Technol. 2013, 11, 471-478. [CrossRef]

29. Geng, R.; Mansouri, S.A.; Aktas, E. The relationship between green supply chain management and performance: A meta-analysis of empirical evidences in Asian emerging economies. Int. J. Prod. Econ. 2017, 183, 245-258. [CrossRef]

30. Brandenburg, M.; Govindan, K.; Sarkis, J.; Seuring, S. Quantitative models for sustainable supply chain management: Developments and directions. Eur. J. Oper. Res. 2014, 233, 299-312. [CrossRef]

31. Awasthi, A.; Kannan, G. Green supplier development program selection using NGT and VIKOR under fuzzy environment. Comput. Ind. Eng. 2016, 91, 100-108. [CrossRef]

32. Luthra, S.; Garg, D.; Haleem, A. The impacts of critical success factors for implementing green supply chain management towards sustainability: An empirical investigation of Indian automobile industry. J. Clean. Prod. 2016, 121, 142-158. [CrossRef]

33. Pagell, M.; Klassen, R.; Johnston, D.; Shevchenko, A.; Sharma, S. Are safety and operational effectiveness contradictory requirements: The roles of routines and relational coordination. J. Oper. Manag. 2015, 36, 1-14. [CrossRef]

34. Qin, R.; Nembhard, D.A. Workforce agility in operations management. Surv. Oper. Res. Manag. Sci. 2015, 20, 55-69. [CrossRef]

35. Han, J.H.; Wang, Y.; Naim, M. Reconceptualization of information technology flexibility for supply chain management: An empirical study. Int. J. Prod. Econ. 2017, 187, 196-215. [CrossRef]

36. Klassen, R.D.; Whybark, D.C. Barriers to the management of international operations. J. Oper. Manag. 1994, 11, 385-396. [CrossRef]

37. Gualandris, J.; Klassen, R.D.; Vachon, S.; Kalchschmidt, M. Sustainable evaluation and verification in supply chains: Aligning and leveraging accountability to stakeholders. J. Oper. Manag. 2015, 38, 1-13. [CrossRef]

38. Morariu, C.; Morariu, O.; Borangiu, T. Customer order management in service oriented holonic manufacturing. Comput. Ind. 2013, 64, 1061-1072. [CrossRef]

39. Wu, H.-H.; Chang, S.-Y. A case study of using dematel method to identify critical factors in green supply chain management. Appl. Math. Comput. 2015, 256, 394-403. [CrossRef]

40. Xu, X.; He, P.; Xu, H.; Zhang, Q. Supply chain coordination with green technology under cap-and-trade regulation. Int. J. Prod. Econ. 2017, 183, 433-442. [CrossRef]

41. Kumar, S.; Khimsara, S.; Kambhatla, K.; Girivanesh, K.; Matyjas, J.D.; Medley, M. Robust on-demand multipath routing with dynamic path upgrade for delay-sensitive data over ad hoc networks. J. Comput. Netw. Commun. 2013, 2013, 1-13. [CrossRef] 
42. Luthra, S.; Garg, D.; Haleem, A. An analysis of interactions among critical success factors to implement green supply chain management towards sustainability: An Indian perspective. Resour. Policy 2015, 46, 37-50. [CrossRef]

43. Khor, K.-S.; Thurasamy, R.; Ahmad, N.H.; Halim, H.A.; May-Chiun, L. Bridging the gap of green it/is and sustainable consumption. Glob. Bus. Rev. 2015, 16, 571-593. [CrossRef]

44. Tabachnick, B.G.; Fidell, L.S. Using Multivariate Statistics; Pearson Education Limited: Harlow, UK, 2013; p. 1072.

45. Leys, C.; Ley, C.; Klein, O.; Bernard, P.; Licata, L. Detecting outliers: Do not use standard deviation around the mean, use absolute deviation around the median. J. Exp. Soc. Psychol. 2013, 49, 764-766. [CrossRef]

46. Boon Sin, A.; Zailani, S.; Iranmanesh, M.; Ramayah, T. Structural equation modelling on knowledge creation in six sigma dmaic project and its impact on organizational performance. Int. J. Prod. Econ. 2015, 168, 105-117. [CrossRef]

47. Ramanathan, U.; Gunasekaran, A. Supply chain collaboration: Impact of success in long-term partnerships. Int. J. Prod. Econ. 2014, 147, 252-259. [CrossRef]

48. Zyoud, S.H.; Fuchs-Hanusch, D. A bibliometric-based survey on AHP and TOPSIS techniques. Expert Syst. Appl. 2017, 78, 158-181. [CrossRef]

49. Avelar-Sosa, L.; García-Alcaraz, J.L.; Castrellón-Torres, J.P. The effects of some risk factors in the supply chains performance: A case of study. J. Appl. Res. Technol. 2014, 12, 958-968. [CrossRef]

50. Caniëls, M.C.J.; Gehrsitz, M.H.; Semeijn, J. Participation of suppliers in greening supply chains: An empirical analysis of german automotive suppliers. J. Purch. Supply Manag. 2013, 19, 134-143. [CrossRef]

51. Ağan, Y.; Kuzey, C.; Acar, M.F.; Açıkgöz, A. The relationships between corporate social responsibility, environmental supplier development, and firm performance. J. Clean. Prod. 2016, 112, 1872-1881. [CrossRef]

52. Lin, H.-F.; Su, J.-Q.; Higgins, A. How dynamic capabilities affect adoption of management innovations. J. Bus. Res. 2016, 69, 862-876. [CrossRef]

53. Richter, N.F.; Cepeda, G.; Roldán, J.L.; Ringle, C.M. European management research using partial least squares structural equation modeling (PLS-SEM). Eur. Manag. J. 2016, 34, 589-597. [CrossRef]

54. Kock, N.; Moqbel, M. Statistical power with respect to true sample and true population paths: A PLS-based SEM illustration. Int. J. Data Anal. Tech. Strateg. 2016, 8, 316-331. [CrossRef]

55. Kock, N. Hypothesis testing with confidence intervals and $P$ values in PLS-SEM. Int. J. e-Collab. 2016, 12, 1-6. [CrossRef]

56. Liu, H.; Wei, S.; Ke, W.; Wei, K.K.; Hua, Z. The configuration between supply chain integration and information technology competency: A resource orchestration perspective. J. Oper. Manag. 2016, 44, 13-29. [CrossRef]

57. Gunasekaran, A.; Subramanian, N.; Papadopoulos, T. Information technology for competitive advantage within logistics and supply chains: A review. Transp. Res. Part E Logist. Trans. Rev. 2017, 99, 14-33. [CrossRef]

58. Marinagi, C.; Trivellas, P.; Reklitis, P. Information quality and supply chain performance: The mediating role of information sharing. Procedia-Soc. Behav. Sci. 2015, 175, 473-479. [CrossRef]

59. Jabbour, C.J.C.; de Sousa Jabbour, A.B.L. Green human resource management and green supply chain management: Linking two emerging agendas. J. Clean. Prod. 2016, 112, 1824-1833. [CrossRef]

(C) 2018 by the authors. Licensee MDPI, Basel, Switzerland. This article is an open access article distributed under the terms and conditions of the Creative Commons Attribution (CC BY) license (http://creativecommons.org/licenses/by/4.0/). 